\title{
Effectiveness of Case Study in Enhancing Student Learning in Operations Management
}

\author{
Mahour Mellat Parast \\ Department of Economics, Finance, and Decision Sciences \\ University of North Carolina-Pembroke \\ Pembroke, NC 28372, USA \\ E-mail: mahour.parast@uncp.edu
}

\begin{abstract}
The purpose of this study is to investigate the effectiveness of case study on student learning. It has been proposed that student learning outcomes will be improved after using the case analysis. Seven constructs have been developed to measure different aspects related to student learning. Pre-assessment and postassessment of student learning outcomes has been conducted to determine the effectiveness of case study approach in enhancing student learning. The results show that using case analysis significantly improves students' higher-order cognitive domain of learning (HC) and self-efficacy (SE). The paper makes contribution to our understanding of the effectiveness of case study on improving learning outcomes of undergraduate students in operations management. Implications for educators and future research have been outlined.
\end{abstract}

Keywords: case study, learning, operations management

\section{Introduction}

The changes in business environment along with the accelerated rate of innovation have called for new practices in education and learning (Alvani and Gallupe, 2003). Educators and administrators are looking for new tools, techniques, and methodologies to address student learning while coping with the external and internal environmental changes (Hamilton et al., 2000).

Ideally, management educators should achieve two objectives in a classroom: first they need to expose students to the tools and techniques of the subject matter, and at the same time provide a foundation for them to utilize those techniques in practice (Loewenstein et al., 2003). While the advancement of educational technologies and the availability of different course delivery approaches provide educators with more choices than before, the effectiveness of these tools and techniques on student learning have not been objectively validated.
One of the pedagogical approaches that have been used in management education is case analysis (Dooley and Skinner, 1977; Banning, 2003). According to Hammond (2002:1) case method is "the most relevant and practical way to learn managerial skills". While cases are supposed to provide a "description of real business situations that serve as a metaphor of a particular set of problems" (Shapiro, 1984:1) cases may not be able to achieve their promises due to their inability to capture the complexity and entirety of the business environment and organizational life (Liang and Wang, 2004). In addition, cases often ignore important research findings and may not incorporate them thereby lacking the scientific rigor (Shugan, 2006). Our understanding on the usefulness of teaching cases is heavily based on anecdotal evidence, and there has been little empirical investigation on the effectiveness of case study on enhancing student learning, especially for undergraduate students. 
The purpose of this study is to determine the effect of case study on student learning in a course on operations management. As a required course in undergraduate business curriculum, students are exposed to a variety of concepts (e.g. manufacturing strategy), tools (e.g. quality control), and techniques (e.g. line balancing) in the course. The course has been designed on a modular basis where each chapter covers a topic related to operations management. Because of the modular structure of the course, students cannot effectively relate the concepts from one chapter to another chapter, and there has been little emphasis on the interconnectedness among different concept/ theories. It was expected that utilizing case study in the operations management can improve student learning, and can enhance their knowledge and learning of the subject.

\section{The Role of Case Study in Business Education}

The importance of using case study in business education is well documented in the literature (e.g. Shaprio, 1988; Bruns, 1993; Corey, 1998; Hammond, 2002; Saladin and Shafer, 2006). According to Lawrence (1953: 215) a case is "the vehicle by which a chunk of reality is brought into the classroom to be worked over by the class and instructor." A case provides an opportunity for the students to view a real problem from the viewpoint of a decision maker (Erskine et al., 1981). Through reading cases students can understand, analyze, and capture the complexity of a business situation. In other words, an effective case analysis relates organizational theory to practice.

Cases help students analyze and discuss written versions of real events, where it helps them to capture the ambiguous decision situations of the business world (Benning, 2003).

It has been argued that teaching cases can provide students with both critical and creative skills required for the business environment (Greenhalgh, 2007). Through reading the case and collecting information and facts from the situation, students can logically and rigorously analyze it, and make an informed decision (Desiraju and Gopinath, 2001).

Presenting a real business situation is not an easy task, and there are criticisms that most cases fail to demonstrate the entirety of an organization due to their interpretative nature (Denzin, 1989), and their limited space or time-frame (Mannen et al. 1989). While case method has been extensively used in teaching business courses, there has been little research to determine its effectiveness and impact on student learning (Yoshida et al., 1999). In fact, teaching cases has been popularized based on the premise that it enhances student learning of the real business practice.

It is interesting to mention the different opinions among scholars in business education regarding the effectiveness of case study. While the effectiveness of case study in teaching and learning has been questioned (e.g. Shugan, 2006) others argue that case teaching is an effective way of teaching management theory (e.g. Christensen and Carlile, 2009). However, the validity of the above argument is open to question due to lack of empirical evidence. It is our understanding that conducting empirical research in the effectiveness of case study and student learning can sharpen our insight on the effectiveness of case study on student learning. Therefore, to assess the effectiveness of cases there is a need to relate case teaching to student learning outcomes. By defining specific learning outcomes for a course, we can objectively measure how effective utilization of cases in the course can improve learning outcomes.

\subsection{Case teaching and student learning}

Previous studies have shed some light on the role of case study on student learning. It has been shown that case study can positively affect tolerance of ambiguity so that students can learn how to cope with the complex nature of the business and the decision environments (Banning, 2003). Empirical research supports the effectiveness of case teaching in enhancing student learning outcomes. Böcker (1987) empirically showed that case teaching provides more effective learning environment than lecture teaching. Using a sample of accounting student, Weil et al. (2004) argued that case study enhanced students' competencies - their ability to evaluate situations from multiple perspectives.

As Liang and Wang (2004) reported the majority of research in case study has been limited to administering and conducting the case and little empirical study has been conducted on the underlying assumption of the link between case 
study and learning outcomes. "There is virtually no empirical study designed specifically to examine the underlying frameworks and assumptions embedded in MBA teaching cases" (Wang and Liang, 2004:398). It is the purpose of this paper to determine if case study has significant and positive effect on student learning.

This study is different from previous research in several ways. First, this study defines several constructs to measure learning outcomes which have not been addressed in previous studies. In that regard, this study provides a broader and more comprehensive perspective on measuring learning outcomes. Second, this is the first study that measures student learning outcomes in operations management. Finally, in contrast to the previous studies which measured learning using a single construct, we conceptualized and operationalized student learning as a multi-dimensional construct. In that regards, it determines the link between case study and improvement in specific learning outcomes. Accordingly, this study contributes to our understanding of the effectiveness of case study in student learning.

\section{Variables and Measurements}

For the purpose of this paper seven constructs have been defined to capture the learning outcomes of students in operations management. The importance of these learning outcomes have been addressed in previous studies (Walls, 2000; Banning, 2003; Desiraju and Gopinath, 2001; Greenhalgh, 2007). The abbreviation in the parentheses refers to the variables used in the data analysis section.

General attitude toward the subject matter (GA): measures general attitude of students about the subject (Böcker, 1987).

Relevance of the subject matter to life and society (RS): measures the relevance of the course in practice, to life and society (Hirschhorn, 1989).

Ease of learning subject-matter (EL): measures the level of difficulty of the subject matter (Böcker, 1987). Higher-order cognitive domain of learning (HC): measures higher-order skills such as decision making and problem solving as wells as understanding and applying course concepts (Walls, 2000; Banning, 2003; Mbarika, 2003).
Self-efficacy (SE): refers to improving self-confidence, and higher level of accomplishments (Weil et al., 2004).

Impact on team working (IT): addresses students skills in working in teams such as interpersonal skills, listening to others, and interactions with team members (Desiraju and Gopinath, 2001; Loewenstein et al., 2003).

Communication skills (CS): deals with abilities such as writing, presentation and informal communication (Desiraju and Gopinath, 2001; Lyons, 2008).

\section{1 Hypotheses}

The utilization of case study in the classroom is based on the premise that it will improve student learning. Due to the interdisciplinary nature of the course we expect that utilizing case study in operations management will enhance student learning outcomes. First, the case integrates and relates a variety of concepts that have been covered in several chapters (e.g. operations strategy, resource allocation, and project management). Second, case study serves as a vehicle to demonstrate the application of operations management techniques in practice. Therefore, with reference to the above seven constructs it is expected that using case study will significantly improve student learning outcomes. Accordingly, it is hypothesized that

$\mathrm{H}_{1}$ : Using case study will significantly improve students' general attitude toward the subject matter.

$\mathrm{H}_{2}$ : Using case study will significantly improve students' understanding of the relevance of the subject matter to life and society.

$\mathrm{H}_{3}$ : Using case study will significantly improve students' higher-order cognitive domain of learning.

$\mathrm{H}_{4}$ : Using case study will significantly improve students' self-efficacy.

$\mathrm{H}_{5}$ : Using case study will significantly improve students' ease of learning subject matter.

$\mathrm{H}_{6}$ : Using case study will significantly improve students' team working.

$\mathrm{H}_{7}$ : Using case study will significantly improve students' communication skills. 


\section{Methodology}

\subsection{Survey instrument}

A survey instrument was used to gather information on student learning outcomes. The instrument has been developed at the Laboratory for Innovative Technology and Engineering Education (LITEE). It captures seven outcomes related to student learning. A 5-point Likert system scale (an interval scale) was used for collecting information regarding student learning outcomes. The scale ranged from 1 to 5 . Information about the cases and the survey instrument can be obtained from the following website: www.littee.org. The survey also contained some open-ended questions.

\subsection{Participants}

The participants in the study were students in operations management in spring 2009. Students take operations management at the fourth year of their programs. There were 22 students in the class, which was a collection of white, African-American Asian, and Native American (two were absent while collecting the data on pre-test) students. The class has a balanced composition of traditional and nontraditional (working adults) students.

\subsection{Case study procedure}

For the purpose of this study, students were assigned to work as a team and read the assigned case study on a $\$ 360$ million company (Superstar
Specialists, Inc.) with five business segments. The case study was related to R\&D project selection. CEO of Superstar Specialties, Inc. was faced with the decision to allocate resources between fifteen proposed R \& D projects. The board had allocated him $\$ 3.3$ million to spend on $R \& D$ for the next budget year.

The students could select their own team members to work with them. Each team consisted of four or five members. To assess student learning, their learning outcomes have been measured prior to the implementation of the case (pre-assessment). Later, after the completion of the case, a post-test has been administered to measure their learning skills. In addition, open-ended questions were used to capture the learning experience of students.

\section{Data Analysis and Results}

The mean and standard deviations for each variable along with other statistics have been provided in the tables (Table 1 and Table 2). To check for normality, skewness and kurtosis has been calculated. At the level of significance of 0.01 , the critical value of skewness is \pm 1.174 . For kurtosis, a value between -1.21 and 2.86 satisfies the requirement of normality.

In addition, the normality of the constructs was checked using Kolmogorov-Smirnov (KS) Z-test. From the information provided and the result of the KS Z-test it was concluded that the requirement for normality has been satisfied.

Table 1. Descriptive Statistics (Pre-test)

\begin{tabular}{|c|c|c|c|c|c|c|c|c|c|}
\hline \multirow{2}{*}{ Constructs } & N & \multicolumn{2}{|c|}{ Mean } & Std. Deviation & Variance & \multicolumn{2}{c|}{ Skewness } & \multicolumn{2}{c|}{ Kurtosis } \\
\cline { 2 - 9 } & Statistic & Statistic & Std. Error & Statistic & Statistic & Statistic & Std. Error & Statistic & Std. Error \\
\hline & & & & & & & & \\
GA & 20 & 14.3500 & .51440 & 2.30046 & 5.292 & -.449 & .512 & -.435 & .992 \\
RS & 20 & 8.3000 & .49258 & 2.20287 & 4.853 & -.063 & .512 & -.527 & .992 \\
EL & 20 & 16.4500 & .68239 & 3.05175 & 9.313 & -.353 & .512 & .067 & .992 \\
HC & 20 & 11.2500 & .61505 & 2.75060 & 7.566 & -.138 & .512 & 1.499 & .992 \\
SE & 20 & 13.4500 & .54035 & 2.41650 & 5.839 & .528 & .512 & 2.617 & .992 \\
IT & 20 & 10.6500 & .37187 & 1.66307 & 2.766 & .242 & .512 & .377 & .992 \\
CS & 20 & 8.0000 & .31623 & 1.41421 & 2.000 & .372 & .512 & -.469 & .992 \\
Valid N & 20 & & & & & & & & \\
\hline
\end{tabular}


Table 2. Descriptive Statistics (Post-test)

\begin{tabular}{|c|c|c|c|c|c|c|c|c|c|}
\hline \multirow{2}{*}{ Constructs } & N & \multicolumn{2}{|c|}{ Mean } & Std. Deviation & Variance & \multicolumn{2}{c|}{ Skewness } & \multicolumn{2}{c|}{ Kurtosis } \\
\cline { 2 - 10 } & Statistic & Statistic & Std. Error & Statistic & Statistic & Statistic & Std. Error & Statistic & Std. Error \\
\hline GA & 22 & 15.2273 & .49207 & 2.30799 & 5.327 & .437 & .491 & 1.446 & .953 \\
RS & 22 & 8.8182 & .58345 & 2.73664 & 7.489 & .746 & .491 & -.154 & .953 \\
EL & 22 & 17.0000 & .78954 & 3.70328 & 13.714 & -.557 & .491 & -.917 & .953 \\
HC & 22 & 15.0455 & .95681 & 4.48784 & 20.141 & .322 & .491 & -.904 & .953 \\
SE & 22 & 16.4545 & .99507 & 4.66729 & 21.784 & .802 & .491 & .135 & .953 \\
IT & 22 & 12.3636 & .75749 & 3.55294 & 12.623 & .588 & .491 & .418 & .953 \\
CS & 22 & 9.0455 & .51167 & 2.39995 & 5.760 & .100 & .491 & -1.450 & .953 \\
Valid N & 22 & & & & & & & & \\
\hline
\end{tabular}

\subsection{Reliability and validity of the instrument}

Table 3 shows Cronbach's coefficient alpha for the seven constructs. The Cronbach's alpha is used to measure the internal consistency and reliability of the instrument (Cronbach, 1951). A value of 0.7 or higher is an acceptable value for survey research (Nunally and Bernstein, 1994; Streiner, 2003).

A review of the reliability measures for the constructs reveals issues with few of them. While higher level of reliability is generally recommended, a cut-off value of 0.5 for new constructs and new measures are acceptable. In that regards, two constructs in pre-test $(\mathrm{GA}=0.399 ; \mathrm{EL}=0.471)$ and one construct in the post-test $(\mathrm{GA}=0.034)$ have low reliability.

Further analysis has been conducted to improve reliability. A few questions in some constructs have been worded reversely. This may have been overlooked by the students or they may have

Table 3. Reliability (pre-test)

\begin{tabular}{|l|c|c|}
\hline \multicolumn{1}{|c|}{ Construct } & Items & Cronbachís Alpha \\
\hline General attitude toward subject (GA) & 6 & 0.399 \\
Relevance of the subject matter to life & 4 & 0.748 \\
and society (RS) & & \\
Ease of learning subject matter (EL) & 6 & 0.471 \\
Higher order cognitive domain of learning (HC) & 6 & 0.894 \\
Self-efficacy (SE) & 6 & 0.626 \\
Impact on team working (IT) & 5 & 0.599 \\
Communication skills (CS) & 3 & 0.604 \\
\hline
\end{tabular}

confused them in providing their scores to these questions. By removing these questions from the constructs reliability of the constructs could be improved. Therefore, two questions from GA and one question from EL have been removed. By employing the above procedure, the new measures of reliability have been calculated (Table 5). To establish the unidimensionality of factors, an exploratory factor analysis using principal component extraction with a varimax rotation was performed on constructs. The examination of eigenvalues and screen test results revealed seven factors which was consistent with our initial conceptualizing of constructs.

\subsection{Correlation}

The correlation between variables is presented in Table 6 and Table 7. A comparison of the correlation among constructs in Table 6 and Table 7 reveals some interesting findings.

Table 4. Reliability (post-test)

\begin{tabular}{|l|c|c|}
\hline \multicolumn{1}{|c|}{ Construct } & Items & Cronbachís Alpha \\
\hline General attitude toward subject (GA) & 6 & 0.034 \\
Relevance of the subject matter to life & 4 & 0.662 \\
and society (RS) & & \\
Ease of learning subject matter (EL) & 6 & 0.731 \\
Higher order cognitive domain of learning (HC) & 6 & 0.905 \\
Self-efficacy (SE) & 6 & 0.907 \\
Impact on team working (IT) & 5 & 0.888 \\
Communication skills (CS) & 3 & 0.769 \\
\hline
\end{tabular}


Table 5. Reliability of the constructs

\begin{tabular}{|l|c|c|c|}
\hline \multicolumn{1}{|c|}{ Construct } & Items & $\begin{array}{c}\text { Alpha } \\
\text { (post-test) }\end{array}$ & $\begin{array}{c}\text { Alpha } \\
\text { (post-test) }\end{array}$ \\
\hline General attitude toward subject (GA) & 4 & 0.574 & 0.638 \\
$\begin{array}{l}\text { Relevance of the subject matter to life } \\
\text { and society (RS) }\end{array}$ & 4 & 0.748 & 0.662 \\
Ease of learning subject matter (EL) & 5 & 0.628 & 0.835 \\
Higher order cognitive domain & 6 & 0.894 & 0.905 \\
of learning (HC) & 6 & 0.626 & 0.907 \\
Self-efficacy (SE) & 5 & 0.599 & 0.888 \\
Impact on team working (IT) & 3 & 0.604 & 0.769 \\
Communication skills (CS) & & & \\
\hline
\end{tabular}

For example, while general attitude towards the subject matter is significantly correlated with three constructs in pre-test (with HC, SE and IT) it is significantly correlated with all constructs in posttest. In addition, communication skills, while not being significantly correlated with other constructs in the pre-test, is significantly correlated with all constructs except ease of learning (EL). Overall, there is stronger correlation among variables in the posttest compared to the pre-test. This could be interpreted as an improvement in validity of the instrument since strong correlation among constructs (e.g. GA and EL, GA and SE, and GA and IT) is theoretically expected.

Table 6. Correlations (pre-test)

\begin{tabular}{|l|r|r|r|r|r|r|r|}
\hline Construct & GA & RS & EL & HC & SE & IT & CS \\
\hline GA Pearson Correlation & 1 & .347 & .295 & $.593^{* *}$ & $.485^{*}$ & $.645^{* *}$ & .254 \\
$\quad$ Sig. (2-tailed) & & .134 & .207 & .006 & .030 & .002 & .279 \\
RS Pearson Correlation & .347 & 1 & .278 & $.447^{*}$ & .418 & $.533^{*}$ & .169 \\
$\quad$ Sig. (2-tailed) & .134 & & .235 & .048 & .066 & .016 & .476 \\
EL Pearson Correlation & .295 & .278 & 1 & .192 & .134 & .317 & -.397 \\
$\quad$ Sig. (2-tailed) & .207 & .235 & & .418 & .574 & .173 & .083 \\
HC Pearson Correlation & $.593^{* *}$ & $.447^{*}$ & .192 & 1 & $.608^{*}$ & $.492^{*}$ & .352 \\
Sig. (2-tailed) & .006 & .048 & .418 & & .004 & .028 & .128 \\
SE Pearson Correlation & .485 & .418 & .134 & $.608^{* *}$ & 1 & .303 & .354 \\
Sig. (2-tailed) & .030 & .066 & .574 & .004 & & .194 & .125 \\
IT Pearson Correlation & $.645^{* *}$ & $.533^{*}$ & .317 & $.492^{*}$ & .303 & 1 & .358 \\
Sig. (2-tailed) & .002 & .016 & .173 & .028 & .194 & & .121 \\
CS Pearson Correlation & .254 & .169 & -.397 & .352 & .354 & .358 & 1 \\
Sig. (2-tailed) & .279 & .476 & .083 & .128 & .125 & .121 & \\
N & 20 & 20 & 20 & 20 & 20 & 20 & 20 \\
\hline
\end{tabular}

Table 7. Correlations (post-test)

\begin{tabular}{|l|r|r|r|r|r|r|r|}
\hline Construct & GA & RS & EL & HC & SE & IT & CS \\
\hline GA Pearson Correlation & 1 & $.766^{* *}$ & $.555^{* *}$ & $.783^{* *}$ & $.777^{* *}$ & $.580^{* *}$ & $.668^{* *}$ \\
$\quad$ Sig. (2-tailed) & & .0001 & .007 & .0001 & .0001 & .005 & .001 \\
RS Pearson Correlation & $.766^{* *}$ & 1 & $.599^{* *}$ & $.741^{* *}$ & $.529^{*}$ & $.610^{* *}$ & $.473^{*}$ \\
$\quad$ Sig. (2-tailed) & .000 & & .003 & .000 & .011 & .003 & .026 \\
EL Pearson Correlation & $.555^{* *}$ & $.599^{* *}$ & 1 & .376 & .418 & .078 & .280 \\
$\quad$ Sig. (2-tailed) & .007 & .003 & & .085 & .053 & .730 & .206 \\
HC Pearson Correlation & $.783^{* *}$ & $.741^{* *}$ & .376 & 1 & $.676^{* *}$ & $.692^{* *}$ & $.694^{* *}$ \\
Sig. (2-tailed) & .0001 & .0001 & .085 & & .001 & .0001 & .0001 \\
SE Pearson Correlation & $.777^{* *}$ & $.529^{*}$ & .418 & $.676^{* *}$ & 1 & $.593^{* *}$ & $.891^{*}$ \\
Sig. (2-tailed) & .000 & .011 & .053 & .001 & & .004 & .0001 \\
IT Pearson Correlation & $.580^{* *}$ & $.610^{* *}$ & .078 & $.692^{* *}$ & $.593^{* *}$ & 1 & $.562^{* *}$ \\
Sig. (2-tailed) & .005 & .003 & .730 & .000 & .004 & & .006 \\
CS Pearson Correlation & $.668^{* *}$ & $.473^{*}$ & .280 & $.694^{* *}$ & $.891^{* *}$ & $.562^{* *}$ & 1 \\
Sig. (2-tailed) & .001 & .026 & .206 & .0001 & .0001 & .006 & \\
N & 22 & 22 & 22 & 22 & 22 & 22 & 22 \\
\hline
\end{tabular}

\subsection{Assessment of Students' Learning Improvement}

A t-test has been used to compare pre-test and posttest learning outcomes. A few steps should be taken before using the t-test. First, the assumption of normality needs to be met. This has been done using measures of skewness and kurtosis. Furthermore, to conduct the t-test samples need to have equal variances. Leven's test of homogeneity of variance shows that there is no significant difference in variance between the pre-test and post test learning outcomes.

Table 8 shows the result of the t-test. The findings suggest that there is significant improvement in higher-order cognitive domain of learning (HC) and self-efficacy (SE).

To further validate the findings of the study, a non-parametric test has been used to take into account the small sample size and the inequality of the sample size between pre-test and the post-test. Using Wilcoxon Singed Rank test, it is found that there is significant difference between higher-order cognitive domain of learning (HC) and self-efficacy (SE) in pre-test and pos-test. This finding reconfirms the result of the t-test supporting significant improvement in $\mathrm{HC}$ and SE.

\subsection{Open-ended questions}

As part of the survey students were asked to answer a few open-ended questions regarding their opinion 
Table 8. Result of the t-test

\begin{tabular}{|c|c|c|l|}
\hline Construct & t-value & t-value & \multicolumn{1}{|c|}{ Result } \\
\hline GA & 0.657 & 0.519 & $\mathrm{H}_{1}$ is not supported. \\
RS & 0.544 & 0.593 & $\mathrm{H}_{2}$ is not supported. \\
EL & 0.001 & 0.999 & $\mathrm{H}_{3}$ is not supported. \\
HC & 3.576 & 0.002 & $\mathrm{H}_{4}$ is supported. \\
SE & 2.127 & 0.047 & $\mathrm{H}_{5}$ is supported. \\
IT & 1.759 & 0.095 & $\mathrm{H}_{6}$ is not supported. \\
CS & 1.396 & 0.179 & $\mathrm{H}_{7}$ is not supported. \\
\hline
\end{tabular}

on improving teaching and learning experience in the classroom. The questions addressed issues such as students' previous experience with the subject, the instructor's teaching style, students' team work experience, and the usefulness of the course in their career. We asked open-ended question for both surveys (pre-test and post-test). We were interested in identifying effective teaching strategies that could help students to better understand the subject (operations management). Student emphasized the following themes as effective teaching strategies and learning outcomes in operations management before they worked on the case study (pre-test):

1. Working in teams

2. Using case study

3. Enhancing decision making and critical thinking

For example one student said, "Independent working and team working help me to learn new material". Another student mentioned, "Team work seems to be the most helpful and the most in need of focus in a class". One commented that, "case studies would be useful to understand [course material]".

Reviewing and analyzing students' responses to the survey questions after implementing the case generated the following themes:

1. Decision making and critical thinking

2. Better understanding of the subject

3. The effect of case study on team work

4. Link to the practice of management

One student said, "We all have different opinions but communications and working together to discuss was very helpful". Or, one said, "[the case] was very beneficial, helping me to understand the concept better". Another student commented, "The multi-media case study was very engaging and forced me to think more critically". One student said, "The case helped [me] learn teamwork, and how to delegate work assignments". Another student said, "The case [was] very beneficial because it gave you a chance to read and respond to things that you will be facing in the management field".

Overall, analysis of students' opinion on improving teaching and learning experience in the classroom revealed that using the case study has helped them to achieve higher level of critical thinking, better understanding of the subject, and satisfaction with team work. These findings are consistent with the results from the t-test, where higher-order cognitive domain of learning (HC) and self-efficacy (SE) were significantly improved after implementing the case.

\section{Discussion}

This study was designed to determine the effect of case study on student learning. By defining seven constructs students' perception (learning outcomes) have been measured before and after implementing the case. This is one of the few empirical studies on the effect of case study on student learning. In that regard, it contributes to our knowledge and understanding of cases in enhancing student learning.

Using a t-test, the mean for each construct for pre-test and post-test were compared. The results show that there is significant improvement in two learning outcomes: Higher-order cognitive domain of learning (HC), and self-efficacy (SE). While the averages for other constructs have been improved, these improvements have not been statistically significant. One possible explanation for this is the small sample size; it may be difficult to detect significant improvements in small sample size. In addition, small sample size may cause some concern regarding the validity of the factor analysis. While a sample size of 100 or larger or a minimum ratio of 5:1 (five times as many observations as variables to be analyzed) has been recommended in the literature (Hair et al., 2006) recent findings suggest that factor analysis can yield promising result even with small sample sizes less than 50 (de Winter et al., 2009). Nevertheless, a replication of this study using a larger sample size is highly recommended. 
Regarding the correlation analysis, it is shown that there is significant correlation among constructs in both pre-test and post-test. It is interesting to note that more constructs are correlated in the post-test comparing to the pre-test. Students' attitude towards the course seems to be correlated with all of the constructs after implementing the case. This may suggest that through implementing the case, students had the opportunity to relate the theory/concept of operations management to its practice. Therefore, there is more appreciation and understanding of the course (due to their higher level of understanding of the course and therefore their interest). Due to the small sample size it is not possible to determine whether changes in students' attitude towards the course contributed to changes in other constructs. Utilizing Latent Growth Model (LGM) is a useful technique that helps to determine the pattern of change in the latent variable. This helps to identify whether changes in one latent variable is due to changes in another variables. We were unable to conduct this analysis due to the limitation with the small sample size.

Analysis of open-ended questions both before and after implementing the case showed that working in teams, case study, and enhancing critical thinking and decision making skills were areas that students were emphasizing. The review of students' responses after implementing the case revealed that the above topics were addressed by the case and students were satisfied with their case study experience.

This study also provides insight on the application of case study for undergraduate students. Previous studies have provided a few concerns regarding the usefulness of case study for undergraduate students. It has been argued that prior knowledge of the subject can motivate students to deeply engage in the case (Kleinfeld, 1992). Nontraditional students tend to contribute more to the cases than traditional students (Lundeberg 1993a; Lundeberg 1993b). The findings of the study suggest that effective implementation of case study for undergraduate students can overcome some of the previous problems associated with case analysis. More importantly, implementation of case study has shown to have significant effect on two learning outcomes, and have improved the other outcomes (but not significantly); therefore, it could be regarded as a useful tool in teaching undergraduate courses, specifically in operations management. The nature of operations management as an interdisciplinary course makes case analysis a useful tool to enhance student learning and relate the principles and theories of operations management to practice.

\subsection{Implications for teaching and learning}

The findings of this study provide insight for instructors and educators regarding the effectiveness of case study on student learning. It is recommended that instructors use case study as an integral part of their course due to the positive effect of case analysis in improving student's decision making skills and their self-efficacy.

As Loewenstein et al. (2003) indicated management educators need to address both analysis (analytical and critical thinking skills) and synthesis (integration among different concepts) in a classroom. The modular-based design of operations management provides students with adequate background in analytical skills. What they are lacking is their ability to relate concepts from different chapters/modules in an integrative form. We believe case analysis can be used as a learning tool to teach students how to relate and integrate different concepts in operations management. We do recommend using case analysis as a powerful tool to address synthesis (integration) in operations management.

\section{Limitations}

The study has a few limitations that should be addressed. Small sample size of the study was a major limitation. In that regard, it is suggested that future research replicate this study with a larger sample size. Further attention should be given to improving reliability of the constructs. While the study has an acceptable level of reliability, future implementation of the instrument with a larger sample size can provide a better assessment of reliability. In addition, future studies can provide some measure of student performance (e.g. course related performance) and determine how case study can affect overall student performance in the course. Finally, the findings of this study are limited to undergraduate students and specifically operations management. Care should be 
taken to generalize the findings of this study to other courses in undergraduate curriculum.

\section{Conclusion}

Case study method has been used as a powerful tool to educate students about the practice of business. This study was designed to determine if utilizing case study can improve student learning outcomes in operations management. The findings suggest that case study method significantly improves students' higher-order cognitive domain of learning (HC) and self-efficacy (SE). In that regard, it is suggested that instructors use case analysis as an integral part of their course especially in operations management.

\section{Acknowledgements}

The materials in this paper are based partially upon work supported by the National Science Foundation under grant numbers: 0442531, 0736997, 0623351 and the Laboratory for Innovative Technology and Engineering (LITEE). Any opinions, findings, and conclusions or recommendations expressed in this paper are those of the authors and do not necessarily reflect the views of the National Science Foundation and LITEE.

\section{References}

Alvani, M. and Gallupe, R. (2003) Using information technology in Learning: case studies in business and management education programs, Academy of Management Learning and Education, 2(2), pp. 139-153.

Banning, K. (2003) The effect of the case method on tolerance for ambiguity, Journal of Management Education, 27(5), pp. 556-568.

Böcker, F. (1987) Is case teaching more effective than lecture teaching in business administration? An exploratory analysis, Interfaces, 17 (5), pp. 64-71.

Bruns, W., Jr. (1993) Why I use the case method to teach accounting, Harvard Business School, 9-193-177.

Christensen, C.M. and Carlile, P.R. (2009) Course Research: Using the Case Method to Build and Teach Management Theory, Academy of Management Learning E Education, 8 (2), pp. 240-251.

Corey, E. R. (1998) Case method teaching, Harvard Business School, 9-581-058.
Cronbach, L. (1951) Coefficient alpha and the internal structure of tests, Psychometrica, 16, pp. 297-334.

Denzin, N. K. (1989) Interpretive Biography, Sage Publications, Thousand Oaks, CA.

Desiraju, R. and Gopinath, C. (2001) Encouraging participation in case discussions: A comparison of the MIC and the Harvard case method, Journal of Management Education, 25(4), pp. 394-408.

de Winter, J.C.F., Dodou, D., and Wieringa, P.A. (2009) Exploratory factor analysis with small sample sizes, Multivariate Behavioral Research, 44 (2), pp. 147 - 181

Dooley, A. R. and Skinner, W. (1977) Casing casemethod methods, Academy of Management Review, 2(2), pp. 277289.

Erskine, J. A., Leenders, M. R., and Mauffette-Leenders, L. R. (1981) Teaching with Cases: School of Business Administration, University of Western Ontario, London, Ontario, Canada.

Greenhalgh, A.M. (2007) Case method teaching as science and art: a metaphoric approach and curricular application, Journal of Management Education, 31(2), pp. 181-194.

Hair, Jr., J. F., Black, W. C., Babin, B. J., Anderson, R. E., and Tatham, R. L. (2006) Multivariate Data Analysis (6th ed.), Upper Saddle River, NJ: Pearson Prentice Hall.

Hammond, J. S. (2002) Learning by the Case Method, Harvard Business School, Report Number: 9-376-241, Cambridge, MA.

Hamilton, D., McFarland, D., and Mirchandani, D. (2000.) A decision model for integration across the business curriculum in the 21st Century, Journal of Management Education, 24 (1), pp. 102-126.

Hirschhorn, L. (1989) Professionals, authority, and group life: A case study of a law firm, Human Resource Management, 28 (2), pp. 235-252.

Kleinfeld, J. (1992). Can cases carry pedagogical content knowledge? Yes, but we've got signs of a "Mathew Effect." Paper presented at the annual meeting of the American Educational Research Association, San Francisco, CA.

Lawrence, P. (1953) The preparation of case material. In K. R. Andrews, (Ed.), The case method of teaching human relations and administration, Harvard University Press, Cambridge, MA.

Liang, N. and Wang, L. (2004) Implicit mental models in teaching cases: An empirical study of popular MBA cases in the United States and China, Academy of Management Learning and Education, 3(4), pp. 397-413.

Loewenstein, J., Thompson, L., and Gentner, D. (2003) Analogical learning in negotiation teams: comparing cases promotes learning and transfer, Academy of Management Learning and Education, 2(2), pp. 119-127. 
Lundeberg, M. (1993a) Gender differences in case analysis, Paper presented at the Annual Meeting of the American Educational Research Association, Atlanta, GA.

Lundeberg, M. (1993b) Case discussion in educational psychology, In V. Wolf (Ed.), Improving the Climate of the College Classroom, System Office of Equal Opportunity Programs and Policy Studies, University of Wisconsin, Madison, WI.

Lyons, P. (2008) Case-based modeling for learning management and interpersonal skills, Journal of Management Education, 32(4), pp. 420-443.

Maanen, J. V., Manning, P. K., and Millier, M. L. (1989) Editor's introduction. In N. K. Denzin, (Ed.), Interpretive Biography, Sage Publication, Thousands Oaks, CA.

Mbarika, V.W.A. (2003) Using a multimedia case study approach to communicate information technology concepts at the graduate level- the impact of learning driven constructs, Journal of SMET Education, 4 (1\&2), pp. 28-36.

Nunally, J.C. and Bernstein, J. H. (1994) Psychometric Theory, (3rd Edition), McGraw-Hill, New York, NY.
Brooke A. Saladin and Scott M. Shafer (2006) Turning the Tables on Student Case Analysis Assignments, Decision Sciences Journal of Innovative Education, 4 (1), pp. 169-173.

Shapiro, B. P. (1984) An Introduction to Cases, Harvard Business School Case: 9-584-097, Cambridge, MA.

Shugan, S. M. (2006) Save research - Abandon the case method of teaching, Marketing Science, 25 (2), pp. 109115.

Streiner, D.L. (2003) Starting at the beginning: an introduction to coefficient alpha and internal consistency, Journal of Personality Assessment, 80 (1), pp. 99-103.

Walls, M.E. (2000) Case studies for teaching technology: contexts for course content, Journal of SMET Education, 1 (1), pp. 33-36.

Weil, S., Oyelere, P., and Rainsbury, E. (2004) The usefulness of case studies in developing core competencies in a professional accounting program: ANew Zealand study, Accounting Education, 13 (2), pp. 139-169.

Yoshida, Y., Banning, K. C., and Cross, T. C. (1999) Use of the case method in management education, Konodai Keizai Kenkyu, 10(1), pp. 19-33.

Mahour Mellat Parast is an assistant professor of decision sciences and operations management at the School of Business at the University of North Carolina at Pembroke. He received his PhD. in industrial and management systems engineering from the University of Nebraska - Lincoln in 2006. His areas of research are quality management, Six Sigma, and quality management in supply chain. He has published papers in International Journal of Management and Enterprise Development, International Journal of Production Economics, Quality Management Journal, Quality Progress, Management Decision, and Total Quality Management and Business Excellence. He has reviewed papers for Decision Sciences, International Journal of Production Economics, European Journal of Operations Research, and International Journal of Business Logistics. He has served as a reviewer for NSF CAREER award. 